\title{
A Convergent Mobile Infrastructure: Competition or Co-operation
}

\author{
Phillip Olla \\ ${ }^{1}$ Department of Information systems and Computer Science, Brunel University, Uxbridge, London, UK
}

\begin{abstract}
This paper will describe how the various telecommunication networks are converging to create an environment described by this paper as a Convergent Mobile Infrastructure (CMI). The convergent mobile infrastructure spans multiple technologies including fixed telecommunication network, Wireless Fidelity (WIFI) networks and space technologies, and Global System for Mobile Communications (GSM).
\end{abstract}

A business model framework is presented which is derived from the literature to aid the development of viable business models expected from the amalgamation of mobile telecommunication and space infrastructure. With examples for the global mobile telecommunication industry, this theoretical paper will illustrate the importance of technological and organizational co-operation between the various actors. The paper argues that using the business model concept to describe the framework for a convergent mobile infrastructure can increase adoption of competing network technologies.

Keywords: business models, convergent mobile infrastructure, mobile networks technologies.

\section{Introduction}

The explosive growth of mobile services over the last two decades has changed mobile communications from a struggling niche market to a fundamental constituent of the global telecommunication industry. In some countries such as Finland, Taiwan, and Hong Kong, the $80 \%$ penetration level has been surpassed [1]. However, despite the high adoption rate, mobile technology is still relatively young [2]. The first mobile commercial service offered in Japan in 1979 failed. However a later initiative launched in Nordic countries in 1981 became a huge success globally, which demonstrates the viability and the demand for a mobile infrastructures [2].
This paper introduces the concept of a convergent mobile infrastructure as the future for the mobile telecommunication industry; a convergent mobile infrastructure is constituted of various wireless infrastructures, joined up to create a seamless mobile infrastructure, each with its own unique features becoming a pervasive element of modern society.

There are significant benefits that can be realized from converging disparate mobile communication network technologies into a seamless service. Technologies such as fixed telecommunication, wireless fidelity ( $\mathrm{WiFi}$ ) networks, Global System for Mobile Communications (GSM) networks and space technologies are slowly being integrated to create the concept of a convergent mobile infrastructure. Currently, the full potentials of communication networks are not being realized due to a lack of technical and economical integration of the various network technologies.

This paper aims to use the business model concept to encourage the technological foresight of a convergent mobile infrastructure. The current business models exhibited by various telecommunication providers are focused on competition, ignoring the huge potential that can be achieved by convergence and co-operation. This problem is inherent in the business models created independently by various actors. There is no consideration for convergence opportunities. Most of the network providers, such as fixed, satellite and mobile network providers that provide communication technologies, are often competing in the same space rather than concentrating on their core capabilities and cooperating to generate sustainable business models in the current harsh economic environment. 
This paper argues that the approach by which technical system builders (those who design and overcome technical challenges) and entrepreneurs (those who solve the challenge of how to sell innovative services in the new market place) cooperate during the development of wireless networks will make a difference in the diffusion of the innovation and ability of the innovation to survive. Using the business model concept to outline technical actors, pricing models, and technical capabilities provides the vision to design and build the wireless infrastructure with the option to link into similar and indirectly competing technological infrastructures.

The literature offers various explanations for deriving business models on mobile networks in an ineffective manner, due to the evolution of the mobile value chain and market structure outpacing the research [3]. This paper aims to address this confusion by providing an integrated view of the evolving convergent mobile markets, and uses the mobile business model framework to identify market actors in order to encourage the business actors to deliver on the full potential of a convergent mobile infrastructure, which incorporates space technologies.

The paper is structured as follows. The first section provides an overview of the business model literature followed by a discussion on the business model framework presented in this paper. The next section introduces the concept of a mobile convergent infrastructure and uses the business model framework to illustrate how a convergent mobile infrastructure can be used to provide access to services and applications to a user roaming between multiple networks. A brief conclusion provides a summation of the arguments and concepts presented in this paper.

\section{Background: Creating Innovative Business Models}

It is well recognized that introduction of an innovation may affect the diffusion process of another innovation, provided the two are adequately interrelated by function or application [4-6]. Some diffusion models for complementary innovations anticipate a direct interdependency between the innovations [5], such as the relationship between computing hardware and software. In contrast, the focus of this paper is on a technological relationship of a different nature, specifically the tendency of a wireless network innovation (such as GSM) to accelerate the diffusion of another competing wireless infrastructure (such as WIFI). This is likely to be achieved by co-operation rather than competition. This paper presents a conceptual business model framework to illustrate how co-operation between competing wireless network architectures encourages the diffusion of a convergent infrastructure by creating a joint-up telecommunication environment.

All actors in the telecommunication arena need to explore new revenue generating opportunities to increase their market share and sustain their competitive advantage. Although this paper describes the implementation of futuristic new business models, the key enabling factor for the success is not the advancement of the technology, but the convergence of existing technologies and ideas. Similar to mobile commerce business models [3, 7-10], successful mobile convergence business models are likely to be the ones that address the economic peculiarities of mobile systems. These peculiarities include mobility, precision positioning, network effects, broadcasting and communication in a flexible manner.

This paper proposes the use of a business model framework for the creation of innovative business model by analyzing the existing actors' technical capabilities, portfolios, strengths and competencies and adapting their current business models to harness the full possibilities for new revenues and market share.

There are various definitions in the business literature of what constitutes a generic business model, but some fail to pay explicit attention to technology [11]. Others fall short in the area of defining the multiplicity of actors. An appropriate definition is presented below:

"A business model is the architecture of an organization and its network of partners for creating, marketing and delivering value and relationship capital to one or several segments of customers in order to generate profitable and sustainable revenue streams [9].

Literature for generating business models for mobile or wireless propositions is just as complex and perplexing as the generic e-business 
models. An important contribution to the mobile business model literature is the work of Camponovo and Pigneur (2002) which focused on the mobile market actors landscape, and proposed a conceptual tool for identifying key actors, their business models, interactions and their dependencies [8]. Another important contribution is the emphasis on the increasing significance that organizations in the mobile business market attach to building partnerships [12]. With new potential markets opening up, due to the emergence of new technologies, organizations are looking to partners to accomplish the complex mission of service delivery. Identifying partners with access to key functions such as billing and information sharing, appears to be of great importance in the competition and creation of viable business models for the organizations [12].

\section{Developing a Business Model Framework to Generate Viable Convergent Services}

The literature offers various, explanations for business models on mobile networks in a disconcerted manner. The evolution of the mobile wireless value chain and the market structure has outpaced research [3]. The aim of the framework presented in this section and illustrated in Figure 1, is to encourage the business actors and policy makers to deliver on the full potential of local mobile networks (WiFi) space technologies in mobile environments, by providing new ways of thinking about creating in- novative business propositions. All actors operating in the mobile and satellite arena need to explore new revenue generating opportunities to increase their market share and sustain their competitive advantage. This section provides an integrated view of the evolving mobile and satellite value chain, and uses the business model framework to identify market actors that have developed alliances to offer mobile applications and services.

\subsection{Using Alliances to Achieve Competency}

The first element of the framework requires the identification of all the potential actors along with the role they will be expected to perform in order to contribute to the creation of a viable business proposition. Some organizations may incorporate one or more business roles, such as network operator, content aggregator and content provider [13], but, generally, the typical set of actors involved are illustrated in Figure 1. Organizations have to find their position in the value chain, service providers and content providers have to agree on their respective roles for each of the business models [14], allowing each organization to concentrate on what it does best to the development of a viable proposition. An important undertaking that needs to be carried out during the business modelling stage is the identification and differentiation of the actors' competencies, capabilities skills along with the alliances the are needed.

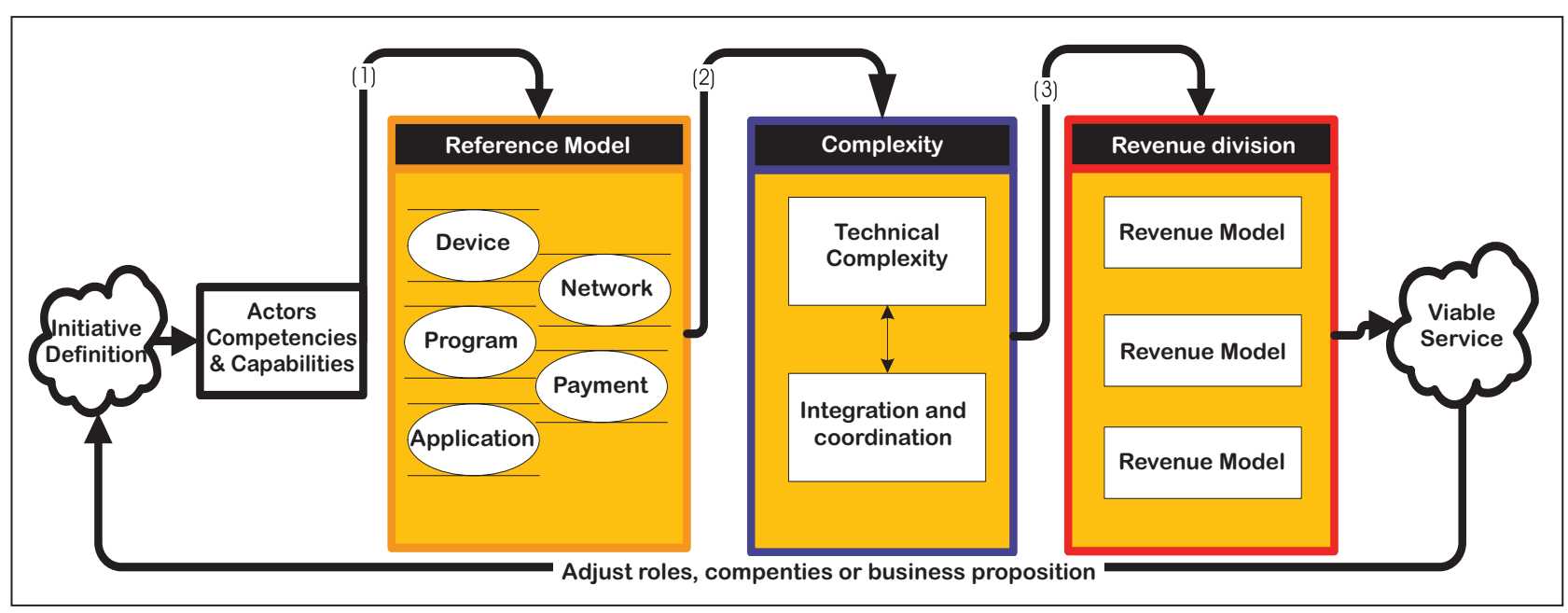

Fig. 1. Business Model Framework. 
When considering the formation of alliances the evidence from the literature suggests that organizations' behavior varies across environments [15]. For high-velocity environments, such as mobile telecommunication and satellite environments, authors have argued that organizations exhibit behavior that differs from behavior in more static environments [16]. In high velocity environments, strategies are often more concerned with change [17], speed [18] and flexibility [19].

There is a new trend on the horizon called network operator alliances that will encourage cooperation between the different types of wireless network providers [20]. The recent alliance of mobile network operators and the fixed line operators aims to tap the emerging market for convergent services. Fixed-mobile convergence provides the opportunity to create additional revenue streams from new value-added services. Another example of co-operation between network operators is the alliance between WiFi operators and mobile network providers to provide seamless roaming capabilities within buildings such as hotels and airports onto mobile networks [21].

These alliances are creating opportunities for innovative mobile devices and services, which enable mobile operators to take the lead in creating the next-generation profitable services. As these services evolve, mobile network operators need to use the creation of innovative business models to encourage initiatives that incorporate convergence with different types of networks such as fixed and local-area wireless network resources such as $\mathrm{WiFi}$ and cable to leverage available higher bandwidth capabilities.

With the new alliances and convergence of satellite and mobile services, there is a risk that current privacy and security issues could be further amplified. Regulators such as International Telecommunications Union (ITU) will need to monitor the situation to implement new privacy legislations relating the location information being widely avaliable and the extent of information sharing amongst operators. Another issue that will need to be addressed in the future is that different legal regimes apply in the various convergent environments such as: Space Law (1967 Outer Space Treaty), Radio Communications Regulations (ITU), International Private Satellite Organizations (INTELSAT) Broadcasting Law/Regulation (TV without Frontiers Directive).

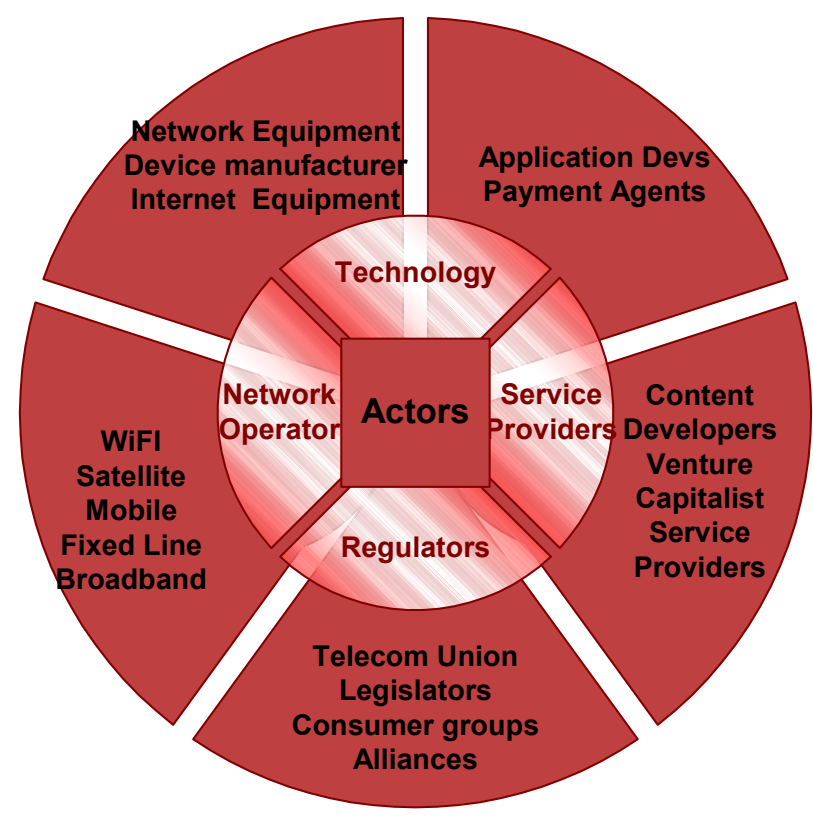

Fig. 2. Actors Map for Mobile-Satellite Propositions.

\subsection{Mobile Convergent Reference Model}

An important element in research of mobile computing is the production of a reference model [22]. Using a reference model in the definition of the business model allows for a consistent discussion of the potential initiatives attributes and features. It structures the discussion in a way that characterises the view of the system as seen by the user and the view of the user as seen by the system. The dimensions of this reference model [23] include the following layers: Application layer, Program layer, Network layer and Device layer. The purpose of the reference model was to provide the ability to describe, with consistency, each proposition from both a business and technical perspective.

\section{Device Layer}

The device layer is the first layer of the reference model, all interactions with the voice or data services are through this interface. This layer deals with the issues such as the user interface, navigation and device software. Some example devices are:

- Voice Centric (VC) devices: The primary purpose of these devices are voice services, they may also have radio or music players. 
- Smartphones: These devices have voice, data along with Personal Information Management (PIM) capabilities. The screens are usually larger than voice devices.

- Personal Digital assistants (PDA): These devices are similar to smartphones with easier input for data, more storage, and larger screens.

- Data card: These are used to connect a laptop to a mobile network at varying speeds dependant on network availability.

\section{Network layer}

The second layer of the reference model is the transmission backbone involved in communications, including transportation, transmission and switching for voice and data. The GSM $2.5 \mathrm{G}, 3 \mathrm{G}$, satellite and WiFi networks have the bandwidth to support wireless data applications and provide mobile internet access. This is fuelling the demand for innovative mobile internet data applications and services.

\section{Program Layer}

This layer deals with the issues of security, business logic, systems logic, data management issues and integration of the devices from the applications.

\section{Payment Layer}

This layer describes the payment model to be applied for the service. The method for collecting the payment from the subscriber should be explicitly stated when defining the proposition by all parties to allow the revenue share model to be agreed [14]. This layer will feed into the financial part of the framework. Examples of payment models include: terminating short message service, subscription, premium short code, pre payment model and event billing.

\section{Application Layer}

In today's environment of wireless applications systems most of a system's components are acquired ready to be installed via systems configuration. The applications layer represents the explanation of what services will be available to the user.

\subsection{Complexity: Co-ordination and Integration Management}

The portion of the framework concentrates on describing the complexity of the innovation required to fulfill the initiative. This task is very subjective and only provides an indication of what needs to be done on a technical level. The next element in the framework asks the business owners to consider how the work should be co-ordinated and managed. Using the technological infrastructure to provide business value, sustain competitive advantage and enable novel and adaptive organizational forms is well recognized by practitioners and academics [24]. The management of end-to-end processes for acquiring suitable products and partners and identification of the skills and competencies that are required is the role of the lead firm in the value chain. The co-ordination of the various actors means the broker in the chain must have a full view of all the activities performed by the independent actors. For example, a location sensing application can potentially incorporate the following actors: mobile network infrastructure, content providers, content developers, content aggregators, hosting providers and application platforms. The role of a broker in the value chain is a colossal task, which is normally carried on by the actor responsible for managing the customer relationship.

\subsection{Financial and Billing Considerations}

The commercial element of the framework is formulated by defining the value proposition of the business initiative. Creating three separate models, Revenue Model, Cost Structure Mode and Profit Model fulfills this activity, determining this portion of the framework, determines the propositions profit model and the ability to survive and compete [25]. The revenue model is an element that measures the ability of a firm to translate the value it offers its customers into money and therefore generate incoming revenue streams. The organizations revenue model can be composed of different revenue streams with all having different pricing models. 
With the mobile convergent model described in more detail in the next section, there are three possible sources of revenue, interconnect traffic from roaming activities, standards call charges and value added services offered. The cost structure model measures all the costs the firm incurs in order to create, market and deliver value to its customers. It identifies a price for resources, assets, activities and partner network relationships [25]. This Profit model is the outcome of the difference between revenue model and cost structure. Currently the voice telecommunication centric model divides propositions at a high level into pre-paid and post-paid services. In the future models this approach will need to change, allowing service transactions to be managed in real-time or near real-time, in order to control expenditure and eliminate credit risk, especially due to the potential of ubiquitous roaming. The billing and collections functions will ultimately become a single role within the business environment. There are considerable challenges to be defined around the settlements and interconnection charging if the true cross networks (Fixed Line $\rightarrow$ Mobile $->$ Satellite, Satellite $->$ Mobile $->\mathrm{WiFi}$ ) roaming becomes a reality. Currently there is the capability to roam between mobile and satellite networks, but this is restricted to one way i.e. some satellite mobile communication users can roam onto the GSM network to make voice calls, but GSM users do not have the capabilities to roam onto a Satellite network for voice or data calls. The number of worldwide satellite subscribers is significantly less than GSM subscribers; this means that the satellite operators would benefit from the increase in ravenue, while the GSM operators would benefit from ubiquitous coverage if such a relationship was ever formed.

Using the business model framework described above, the following section will demonstrate how the use of business model framework can aid the visualization and definition of a viable business proposition.

\section{The Vision of a Convergent Mobile Infrastructure}

This section will describe how various telecommunication networks are converging to create an environment described by this paper as a
Convergent Mobile Infrastructure (CMI). The concept of a convergent mobile infrastructure can be described as relational and ecological [26]. As an ecological system, a mobile convergent infrastructure forms a complex technological system consisting of network, satellites, terminals, antennas and base stations, switching platforms, gateways and other supporting technologies like batteries, accessories, etc. The technological system constantly adapts to the demands of multiple environments including technology push, market pull, and regulatory intervention [2]. It is also in a constant drift due to market changes in technological innovation so that it is not under the control of any specific actor. As an ecological system, a wireless infrastructure can be analyzed through its technological expansion as indicated by its increased functionality, user base growth, traffic volumes, geographical coverage, etc.

The dreams of the pioneers such as Mark Weiser [27], Normand Klenrock [22] that led to the development of concepts such as ubiquitous computing and nomadic computing was of a global convergent mobile infrastructure. The vision describes an infrastructure covering both the developed and developing nations, rural and urban dwellings. To fulfill this vision today would mean developing the business models to integrate disparate network technologies such as satellite, mobile, Wireless Local Area Networks (WiFi or WLAN) as well as wired delivery channels, facilitated by both terrestrial and space-based systems. This vision creates both opportunities and threats to organizations and countries trying to reap the benefits. The extensive range of technological alternatives presents an opportunity to become more globally competitive if the right partners and models are chosen, and for others, it provides a means for accelerating the provision of basic services at a lower cost using appropriate technologies [28].

GSM Mobile communications are largely metropolitan-based while satellite broadband services that extend beyond the reach of urban centers of population offer a celestial extension to terrestrial networks. Therefore, the integration of space technologies with mobile communications technologies encourages the overlapping and ubiquitous use of computer systems, satellite network infrastructure and mobile network infrastructure. The converged technology has 
the potential to deliver meaningful digital content in any of the following formats: communications, broadcasting or information technology.

The key technical challenge to enable the convergence of multiple networks and services is Internet Protocol (IP) technology, and the support for quality of service (QoS). The main technical challenge is not how to combine heterogeneous data links, but how to sustain seamless QoS signaling along with end-to-end support for the service or application. From a nontechnical perspective, the challenge is how to support billing and care activities when a customer is roaming over different networks and crossing borders. The scenario below provides an illustration to highlight the required customer service and the difficulties that operators will face from an operational, security and billing perspective.

\subsection{Mobile Convergence Infrastructure Research Challenges}

The diagram in Figure 3, illustrates the day of a working executive called Bob. During the course of the day, Bob works in his office in the morning, accessing files on the Internet and office Intranet; also running an application that is downloading information from an Internet site. At lunchtime, he begins his long journey home for the weekend, but continues to download the application on the journey. There is currently the technical competence available to seamlessly integrate all forms of wireline and wireless networks and media as illustrated in Figure 3. This will allow access to an array of information from anywhere in the world at any time.

While Bob works in the office, the connection to the systems will be via the corporate infrastructure, which could consist of wireless networking technologies such as Wireless Local Area Network (WLAN); these networks pose technical restrictions that make them unavailable when roaming out of an area. The advantage to these networks is that they are cost effective. To free the user from location restrictions, the device must be fitted with multiple networks adaptors [29].

Once Bob leaves the office, the mobile device will latch on to the enhanced GSM networks or the third generation network. These advanced technological applications are called $2.5 \mathrm{G}$ technologies and include networks such as General Packet Radio Service and Enhanced Data rates for GSM Evolution (EDGE). These networks provide functionality such as: 'alwayson', higher capacity, Internet-based content and packet-based data services enabling services such as color Internet browsing, e-mail on the

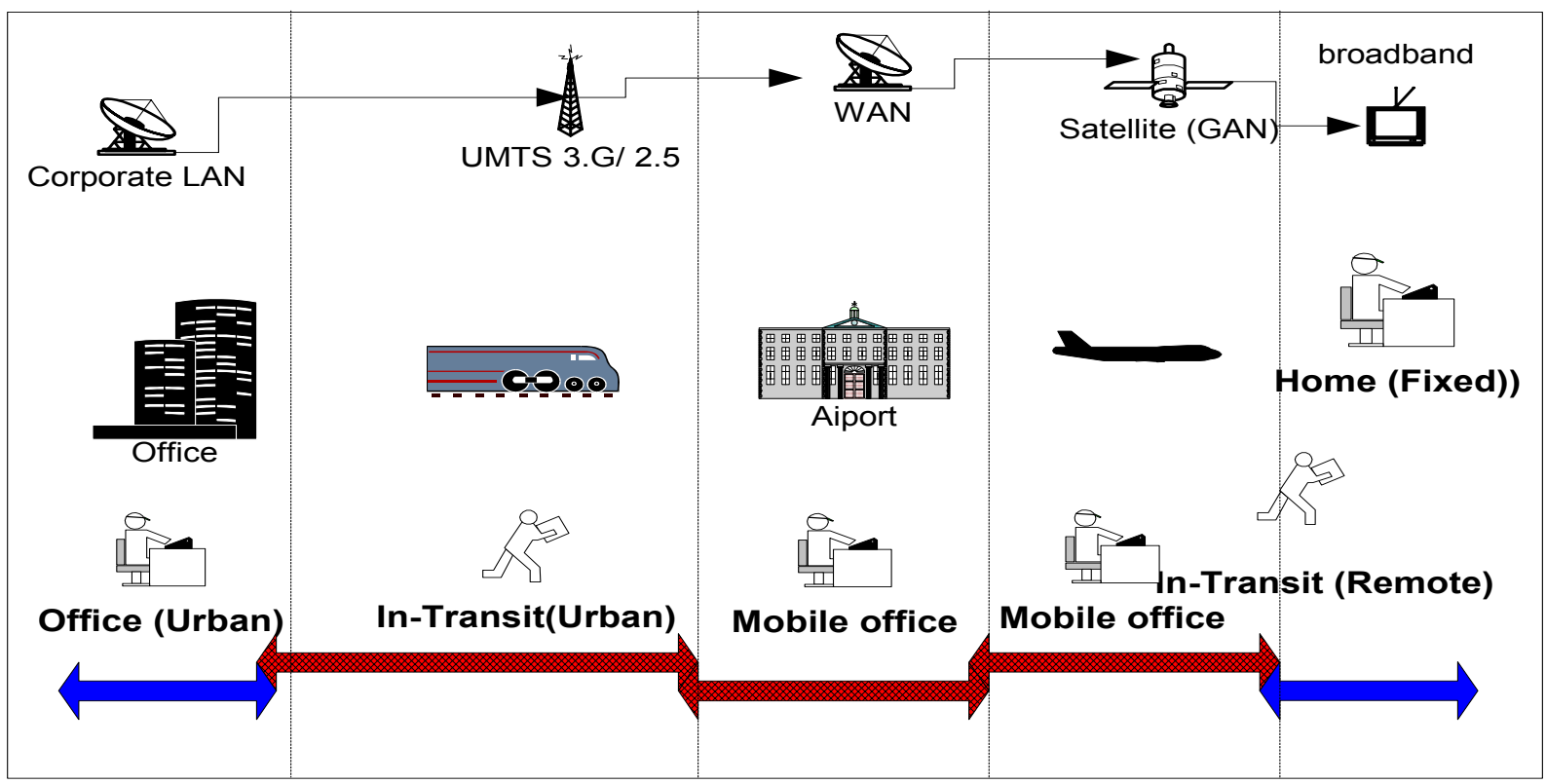

Fig. 3. Convergent Mobile Infrastructure. 
move, visual communications, multimedia messages and location-based services. They allow access to non voice services 3 times faster than a standard $2^{\text {nd }}$ generation network, which means subscribers are able to send and receive data from their portable computers at a speed of up to $28.8 \mathrm{kbps}$; this is currently being upgraded in many networks to rates of and up to $43.2 \mathrm{kbps}$.

On arrival to the train station the system would hand-over to 'In train' or 'On Platform' Mobile Internet service. An example of a railway station mobile Internet infrastructure is the system being tested by the UK Train Operator GNER. The technical solution includes satellite downlinks, multiple cellular uplinks running in parallel, a GPS receiver to track position and an onboard management server. The service scans for the best cellular signal and creates as many GPRS links as necessary to deliver broadband speeds between $100-500 \mathrm{Kbps}$, to end-users.

On arrival at the airport, Bob's device would automatically attach to the wireless local area network (WLAN) he subscribes to via his service provider and this service will continue until his flight takes off. Currently, WLAN hotspots are present at airports, hotels, university campuses and other transit locations where people require wireless access to the Internet or remote access to their company networks. An increasing number of end-user devices are equipped with multiple hardware interfaces for different network technologies such as WLAN and GSM/GPRS. The main commercial challenge is the functionality to enable switching of end-user devices between these different network technologies. This is technically feasible, but at the time of this paper, it was not commercially available for the various operators. Another challenge is to maintain context-aware (enabling) services, such as route planning and scheduling services, and their quality provided to the end-users while they are roaming between hotspots and mobile networks and vice versa [29].

An additional commercial challenge is how to roam between different network technologies from different providers with a single service contract. The business models that will emerge would ask the following questions, i.e. which roles will emerge, which party will play which role and how will tariff structures and the distribution of risks, investments, costs and revenues develop in the future. Research of these questions is currently taking place to address what are plausible and viable of business models for WLAN / mobile integration hotspots [29].

Devices functionality is also a topic that involves interesting technical challenges that will be resolved with time. WiFi / WLAN support is far from universal in current models of laptops and PDAS. Only recent premium models of PDAs are suitable for WiFi. Laptops sold prior to mid-2003 required the purchase of an additional WiFi PC Card. This limits the potential audience for public hotspots; 61 percent of European WiFi hotspot providers surveyed by Jupiter Research cited the lack of an installed base of WiFi equipment as a barrier to greater WiFi usage [30]. However, Wifi's strengths lie in its vastly superior speeds, over five mbps, compared with $9 \mathrm{kbps}$ to $28 \mathrm{kbps}$ on GPRS, or $64 \mathrm{kbps}$ to $384 \mathrm{kbps}$ on UMTS, and accompanying cheaper data volume costs. Hourly WiFi prices in Europe vary from $€ 2.50$ to $€ 10$ per hour for unlimited data volume. GPRS tariffs typically cost $€ 1$ to $€ 3$ per $\mathrm{Mb}$ of data. When both networks are available for a user, the revenue model will need to be integrated with the technical capabilities to ensure that a user is on the best network, from a price and bandwidth perspective.

When Bob takes to the sky, the In-flight system provides Bob with the access to office systems and the Internet. The technical complexity to deliver In-flight mobile data services is not as far-fetched as it seems, the challenge is for the creation of viable business models. Imrasat, the global mobile satellite communications provider [31], has already implemented the In-flight Passenger Entertainment and Communications systems (IPEC). The Imrasat Swift64 service is commercial availability, the service gives aircraft passengers the ability to access Internet-based applications such as email, video streaming and file transfer whilst in the air at ISDN speeds of $64 \mathrm{kbits} / \mathrm{s}$. Currently, up to 80 percent of modern long haul commercial aircraft and over 1,000 corporate jets already have the Imrasat satellite communications antenna infrastructure needed to carry Swift64 services. The platform uses existing aircraft antennas and satellite communication avionics. 
At the end of the flight Bob continues his journey home in his car via remote routes and the GSM $(2.5 / 3 \mathrm{G})$ mobile network is supplemented with coverage via satellite networks. One of the key enablers of the mobile convergent Infrastructure is the use of space technologies with mobile devices. Some organizations consider that space infrastructure will become a key enabling factor for a convergent global mobile telecommunication infrastructure $[28,32$, 33 . A growing range of mobile products and services currently in use today or under development will incorporate space technology such as voice services, radio, broadband internet services, navigation, and observation systems and gravitational research. The current trend of developing business models for applications and services does not go far enough to investigate generic business models for mobile applications and services that are network independent and which incorporate space technology.

Once Bob arrives home, his fixed line broadband operator will provide access to the Internet. If Bob lived in a remote area, then the broadband access could be provided by the satellite service provider as illustrated in business model presented in the next section.

\subsection{Convergent Mobile Infrastructure Business Models}

If the Universal Mobile Telecommunications Service (UMTS) is to live up to its name and achieve a true 'universal' status, more consideration and effort is required to instigate a program to integrate UMTS with space technologies such as satellite communication capabilities and global positioning techniques. Universal mobile satellite systems are touted as the ultimate solution to the problem of covering large areas economically, and serving widely scattered or remote rural customers in both developing and developed countries [34]. For this to happen from a technical basis the satellite component must be integrated with the UMTS to create a more integrated and advanced Mobile Broadband System (MBS) capable of $2 \mathrm{mbs}$. UMTS was designed such that it could be easily integrated into existing $2.5 \mathrm{G}, 3 \mathrm{G}$ and other GSM networks. The mobile broadband communications systems must be capable of the different mobility requirements ranging from stationary (for wireless local loops) to quasistationary (outdoor, office, and industrial environments). From a commercial perspective, there needs to be an introduction of innovative business models, which support revenue share partnerships and joint ventures.

The scenario created by Bob's journey home will lead to the development of new business models as illustrated in Table 1. There are four new business models that can be identified in the diagram such as:

- Transit Corporate Business Model, providing access to mobile office applications, downloading files and video conferencing functionality while the user is traveling (air, land or sea).

- Transit Leisure Business Model, Streaming video, online games, news and multimedia content for the traveler.

- Satellite Broadband Delivering broadband services to remote users using a combination of satellite and GSM technology.

- Data \& Voice Convergent Model, Allowing voice and data services to be handed over to appropriate networks such as GSM, GPRS and Satellite depending on the task being performed, network availability, agreements between operators and the associated costs to the user. This model is described further in Table 1 below.

For the realization of the convergent model described in Table 1, there are some fundamental challenges that need to be addressed. There will be a need for new interfaces between organizations such as content providers and service providers to exchange relevant charging information. This is not completely new as operator and service providers currently exchange billing data. However, there will be the need for new charging protocol for the availability and exchange of real-time (rather than batch-oriented) charging and authorization information. Charging information has to be available from the network elements or from the application servers through to the billing system. There are currently applications that perform this task, but 
Initiative Definition:

This initiative brings together various types of mobile networks to provide true ubiquitous global roaming capabilities to mobile users.

\begin{tabular}{|c|c|c|c|c|c|}
\hline \multicolumn{2}{|l|}{ Actors } & \multicolumn{2}{|l|}{ Competencies and Capabilities } & \multicolumn{2}{|l|}{ Complexity } \\
\hline \multicolumn{2}{|l|}{ Satellite Network Operator } & \multicolumn{2}{|l|}{$\begin{array}{l}\text { Handover capability } \\
\text { Roaming capabilities with UMTS networks } \\
\text { Inter operator billing capabilities }\end{array}$} & \multicolumn{2}{|c|}{$\begin{array}{l}\text { Medium technical complexity } \\
\text { High complexity will involve network } \\
\text { changes }\end{array}$} \\
\hline \multicolumn{2}{|l|}{ Mobile Network Operator } & \multicolumn{2}{|l|}{$\begin{array}{l}\text { Handover capability } \\
\text { Roaming capabilities with Satellite networks }\end{array}$} & \multicolumn{2}{|c|}{ New roaming billing model required } \\
\hline \multicolumn{2}{|l|}{ Device Manufacturers } & \multicolumn{2}{|c|}{$\begin{array}{l}\text { Provide data devices that are capable of roaming } \\
\text { on mobile and satellite networks }\end{array}$} & \multicolumn{2}{|c|}{$\begin{array}{l}\text { Device capabilities similar to Triband devices } \\
\text { but with capabilities to latch on to satellite } \\
\text { networks }\end{array}$} \\
\hline \multicolumn{2}{|l|}{ Content Providers } & \multicolumn{2}{|c|}{$\begin{array}{l}\text { Provide user content, this could be multimedia } \\
\text { such as live streaming, Internet portals or access } \\
\text { to other users. }\end{array}$} & \multicolumn{2}{|c|}{$\begin{array}{l}\text { The complexity will vary depending on the } \\
\text { type of content being delivered }\end{array}$} \\
\hline \multicolumn{2}{|l|}{ Application Developers } & \multicolumn{2}{|c|}{$\begin{array}{l}\text { Provide innovative applications such as location } \\
\text { sensing applications, financial, }\end{array}$} & \multicolumn{2}{|c|}{$\begin{array}{l}\text { The complexity will vary depending on the } \\
\text { type of service }\end{array}$} \\
\hline \multicolumn{2}{|c|}{ Network Infrastructure Vendors } & \multicolumn{2}{|c|}{$\begin{array}{l}\text { Network operators infrastructure vendors develop } \\
\text { interface and gateways to the Internet and other } \\
\text { appropriate networks e.g. Nortel, }\end{array}$} & \multicolumn{2}{|c|}{$\begin{array}{l}\text { The complexity will vary depending on the } \\
\text { type of network and roaming agreements }\end{array}$} \\
\hline \multicolumn{2}{|l|}{ Service Provider } & \multicolumn{2}{|c|}{$\begin{array}{l}\text { They also must work closely with content and } \\
\text { application providers in order to differentiate their } \\
\text { offering. }\end{array}$} & \multicolumn{2}{|c|}{$\begin{array}{l}\text { The complexity will involve developing } \\
\text { appropriate interfaces and managing the } \\
\text { customer billing and care activities }\end{array}$} \\
\hline \multicolumn{6}{|l|}{ Layers } \\
\hline Device & Wireless & Program & \multicolumn{2}{|c|}{ Payment } & Application \\
\hline $\begin{array}{l}\text { Triband Mobile handsets, or } \\
\text { data cards }\end{array}$ & $\begin{array}{l}\text { WiFi } \\
\text { GSM } \\
\text { GPRS } \\
\text { UMTS } \\
\text { Satellite }\end{array}$ & $\begin{array}{l}\text { Network centric hand- } \\
\text { off capabilities } \\
\text { Security } \\
\text { Disconnection control }\end{array}$ & \multicolumn{2}{|c|}{$\begin{array}{l}\text { Subscription to Service } \\
+ \\
\text { Usage dependant on } \\
\text { which network } \\
+ \\
\begin{array}{l}\text { Event charge for a } \\
\text { particular service }\end{array}\end{array}$} & $\begin{array}{l}\text { Location-based services } \\
\text { Mobile Internet facilities } \\
\text { Mobile Office } \\
\text { Multimedia applications }\end{array}$ \\
\hline \multirow{2}{*}{\multicolumn{6}{|c|}{$\begin{array}{l}\text { Revenue will be generated from the providing complimentary services to mobile subscriber user. The revenue will be collected from the } \\
\text { customer by the mobile operator / service provider. } \\
\text { Revenue is earned from user subscriptions and traffic agreements with other ISPs and operators. Currently the Telco centric model divides } \\
\text { propositions at a high level into pre-paid and post-paid services. This model will need to change, allowing service transactions to be managed in } \\
\text { real-time or near real-time, in order to control expenditure and eliminate credit risk especially due to potential of ubiquitous roaming. Billing } \\
\text { and collections will ultimately become a single role within the business environment, handling the account balance for end customers regardless } \\
\text { of whether the account happens to be pre-paid or post-paid, there are considerable challenges to be defined around the settlements and } \\
\text { interconnection charging. }\end{array}$}} \\
\hline & & & & & \\
\hline \multicolumn{6}{|c|}{$\begin{array}{l}\text { Customer Satisfaction } \\
\text { - The minimal loss of service when hand-off occurs. } \\
\text { - Being informed of the charging differential when moving from WiFi }>\text { mobile } \rightarrow \text { satellite if it likely to vary significantly, with the } \\
\text { option to suspend the session } \\
\text { - No loss of data during the network changeover. } \\
\text { - Clear and concise charging rules as opposed to the current bytes model. }\end{array}$} \\
\hline
\end{tabular}

Table 1. Mobile Convergent Business Model. 
there are no mature interface standards. In addition, the settlements and retail charging facility will face a range of changes. The UMTS forum is producing a report highlighting the interorganizational financial settlements issues [14]. In the future, Quality of service (QoS) will be an important variable due to data services that require a guaranteed level of service and support. Customer billing should be performed incorporating the QoS measurements achieved against what was guaranteed. The current implementations of $3 \mathrm{G}$ do not take into account QoS billing features.

Another key factor to the success of the mobile convergent model is the formation of strong alliances between organizations. An example of an alliance that would benefit from partnership with satellite operators is the 'Starmap Mobile Alliance', launched in February 2004. The Starmap mobile alliance currently has nine members: Amena (Spain), O2 (Germany, the UK and Ireland), One (Austria), Pannon GSM (Hungary), Sunrise (Switzerland), Telenor Mobil (Norway) and Wind (Italy), covering a subscriber base of more than 41 million. The Starmap management board comprises representatives from each operator. The Starmap mobile alliance cooperates to provide an environment for innovative and easy-to-use services offering a 'home-away-from-home' experience for subscribers, encompassing the convenience and quality of service to which customers are accustomed to at home. The group has both technical and commercial agreements between the operators, customers benefit from GPRS and Mobile Media Messaging (MMS) roaming, as well as access to familiar services such as voicemail and short-codes whilst traveling in other alliance countries. Alliance members are cooperating on the development of $3 \mathrm{G}$ handsets, and a common distribution agreement has been established providing availability of a standard PDA (Xda II Pocket PC) across alliance networks. The aim of the alliance is to provide seamless mobile voice and data services across the alliance footprint. The alliance worldwide footprint could be significantly increased with an agreement with a mobile satellite operators who would join the alliance to provide ubiquitous accesses to services when roaming in rural areas and traveling (both sea and air).

The global satellite services industry is slowly transforming toward the creation of conver- gent network infrastructures. A convergent network combines both space and mobile and fixed-line connections to deliver a ubiquitous customer signals efficiently and economically. Broadcasting and content service providers are now using both terrestrial and satellite links to provide services. With the new convergent networks, the emphasis is on service, not the technology through which the service is carried. In contrast, conventional satellite-only (or terrestrial-only) network operators put the delivery technology first, and then try to fit the service into their technology's specific parameters and limits. Satellite service providers such as Intelsat have reported revenue-generating result from convergent networks. The organization integrated 25 satellites with numerous terrestrial Points of Presence (PoPs). In turn, these PoPs link to local high-speed telephone loops, which deliver efficient, cost-effective global access. [35]

\section{Conclusion}

This paper presented a vision of the future of mobile communication, which is a convergence of mobile, fixed and satellite technologies to create a truly convergent mobile infrastructure. The environment creates new business opportunities, which can be realized by using appropriate business modeling techniques to identify viable propositions.

The vision of a mobile convergent infrastructure is simultaneously a social and technical concept in that the success of the technology depends both on understanding how the system can be built (how the disparate wireless networks can be integrated to harness the technological potential). The social aspect deals with how to make the proposition attractive to new customers (creating viable business models beneficial to the various business actors and customers). This paper argues that using the concept of the business model apportions the focus on both technical and social positions, allowing innovators to establish a 'technological regime' (Nelson, 1994) that proceeds along particular lines of diffusion that reflect both what technologists understand they can likely achieve, and what entrepreneurs believe customers will buy. 
This paper argues that the co-operation between technical system builders (designers that overcome technical challenges) and entrepreneurs (who solve the challenge of how to sell innovative services in the new market place) is critical for the ability of a network innovation to survive. In order to successfully create a convergent mobile infrastructure, co-operation rather than competition is required between the various types of network providers. The various actors who collaborate in creating a convergent mobile infrastructure will make a difference to the diffusion of the innovation of individual mobile networks as well as the resulting joined-up network.

Using the business model concept to model actors, partnerships, pricing, and technical components of a convergent environment provides the foresight and vision to design and build the wireless infrastructure with the options to link into similar and indirectly competing technological infrastructures. A concerted effort is required in the research and development arena to achieve the convergence of telecommunication network integration, incorporating local networks (WiFi, Bluetooth), satellite networks, GSM 2.5, 3G and fixed line networks. It would be highly unrealistic to assume that every type of communication technology can be integrated, but as long as each scenario such as urban stationary, urban motion, maritime, air, and rural is covered, the global communication infrastructure vision is achievable.

Further work is required to define and develop common service standards with consistent transmission parameters and a radio interface between satellite and terrestrial implementations, along with the billing and roaming capabilities. However, the most important factor will be the increase in co-operation between the operators and the definition of viable business models. This paper has described a structured approach to business model development in the mobilesatellite communication sector, which may be used to aid policy makers and network operators develop innovative business models.

\section{Acknowledgment}

I would like to thank the reviewers for their invaluable comments.

\section{References}

[1] Melody, W.H., Assessing highly imperfect mobile markets, Telecommunications Policy (2001), 25, pp. $1-3$.

[2] Lyytinen, K. AND V.V. FOMIN, Achieving high momentum in the evolution of wireless, infrastructures:the battle over the $1 \mathrm{G}$ solutions, Telecommunications Policy (2002), 26, pp. 149-170.

[3] SABAT, H.K., The evolving mobile wireless value chain and market structure, Telecommunications Policy (2002), 26(9-10), pp. 505-535.

[4] ALPERT, F., Innovator buying behavior over time: the innovator buying cycle and the cumulative effects of innovations, Journal of Production Brand Management (1994), 3(2), pp. 50-62.

[5] Peterson R. AND M. V., Multi-product growth models, in: Sheth J, editor, Research in marketing, 1978, JAI Press, Greenwich (CT), pp. 201-31.

[6] REDMOND, W.H., Interconnectivity in diffusion of innovations and market competition, Journal of Business Research (2002), 58(16).

[7] Maitland, C.F., Bauer, Johannes M. \& WestERVELD, RUDI, The European market for mobile data, Telecommunications Policy (2002), 26(9-10), pp. $485-504$.

[8] Camponovo, G. AND Y. Pigneur, Business Model Analysis Applied to Mobile Business, in Internat. Conference on Enterprise Information Systems (ICEIS), Anger 2003, 2002.

[9] Pigneur, Y., An Ontology for m-Business Models (2000), University of Lausanne, Ecole des HEC, CH-1015 Lausanne.

[10] Tsalgatidou, A. AND E. Pitoura, Business models and transactions in mobile electronic commerce: requirements and properties, Computer Networks (2001), 37(2), pp. 221-236.

[11] Weill, P. AND M.R. Vitale, Place to Space. Migrating to e-business Models, ed. H.B.S. Press, Boston, 2001.

[12] Bouwman, H. AND E.V.D. HAM, Designing metrics for business models describing Mobile services delivered by networked organizations, in 16th Bled Electronic Commerce Conference eTransformation Workshop on concepts, metrics \& visualisation (2003), Bled, Slovenia.

[13] BARNES, S.J., The mobile commerce value chain: analysis and future developments, International Journal of Information Management (2002), 22(2), pp. 91-108.

[14] UMTS-Forum-Report21，Charging, Billing and Payment Views on $3 G$ Business Models, 2002, UMTS: http://www.umts-forum.org/ servlet/dycon/ztumts/umts/Live/en/umts/ Resources_Reports_index. 
[15] BuRns, T., STALKER, G.M., The Management of Innovation, Tavistock, London, 1961.

[16] Thomas, L.G., The two faces of competition: dynamic resourcefulness and the hypercompetitive shift, Organization Science (1996), 7(3), pp. 221242.

[17] EISENhardT, K.M. AND S.L. BROwn, Time pacing: competing in markets that won't stand still, Harvard Business Review (1998), 76(2), pp. 59-69.

[18] EISENHARDT, K.M., Making fast strategic decisions in high-velocity environments, Academy of Management Journal (1989), 32(3), pp. 543-576.

[19] D'AVENI, R.A., Hypercompetition: Managing the Dynamics of Strategic Maneuvering, Free Press, New York, 1994.

[20] BLAU, J., BT heads fixed mobile convergence drive, in Computer Weekly, 2004.

[21] Mike Roberts And D. Beaumont, Wi-Fi Hotspot Operator Case Studies, Planet Wireless, 2003.

[22] KLEINROCK, L., Nomadic computing (keynote address), Telecommunication Systems (1997), 7(1-3), pp. 5-15.

[23] Olla, P. AND N. PATEl, Framework for Delivering Secure Mobile Location Information 1, International Journal of Mobile Communications (2003), 1(3), pp. 289-300.

[24] ORLIKOWsKI, W.J. AND D. ROBEY, Information Technology and the Structuring of Organizations, Information Systems Research (1991), 2, pp. 143169.

[25] AleXANDER Osterwalder, SARRA Ben LAGHA, AND Y. PIGNEUR, An Ontology for Developing e-Business Models, http://inforge.unil.ch/ aosterwa/, 2003.

[26] STAR, S.L., The ethnography of infrastructure, American Behavioral Scientist (1999), 43(3), pp. 377-392.

[27] WeISER, M., Ubiquitous Computing, Computer (1993), 26(10), pp. 71-72.

[28] UNESCAP-Report, Towards a policy framework for integrating space technology applications for sustainable development on the information superhighway, in United Nations Economic and Social Commission for Asia and the Pacific, 2002.

[29] Verhoosel, J., R. STAP, AND A. SALDEN, A generic business model for WLAN hotspots: a roaming business case in the Netherlands, in 1st ACM International Conference on wireless mobile applications and services on wlan hotspots, 2003, ACM Press, San Diego, USA.

[30] FogG, I., M. Mulligan, And M. Gartenberg, Public Wi-Fi: Will It Replace Mobile Networks?, in Jupiter Research, 2004, www. jupiterresearch. com.
[31] Imrasat-Swift64, Inmarsat Announces Availability of the 64Kbit/s Mobile Office in the Sky, 2002, http://www.inmarsat.com/swift64/ press_1.htm.

[32] OECD, Organization for Economic co-operation and Development (OECD), in Commercialisation of space and development of space infrastructure, 2003, International Futures program.

[33] UN-Program, Environment and Natural Resources Management: Space Technology Applications Section, in The Intergovernmental Consultative Committee: on the Regional Space Applications Programme for Sustainable, 2002.

[34] Muratore, F., UMTS Mobile Comunication of the Future, Wiley, Chicester, 2001.

[35] CAReless, J., Hybrid Networks: A Winning Partnership For Satellite, in Via Satellite, 2004.

Received: July, 2004 Revised: August, 2004 Accepted: August, 2004

Contact address: Phillip Olla Department of Information Systems and Computing Brunel University Uxbridge, London United Kingdom e-mail: Phillip.olla@brunel.ac.uk

PHILlIP OLLA is a research assistant at the Department of Information Systems and Computing of Brunel University. His area of interest include mobile communication, incorporating space technologies into everyday applications and convergent technologies. 